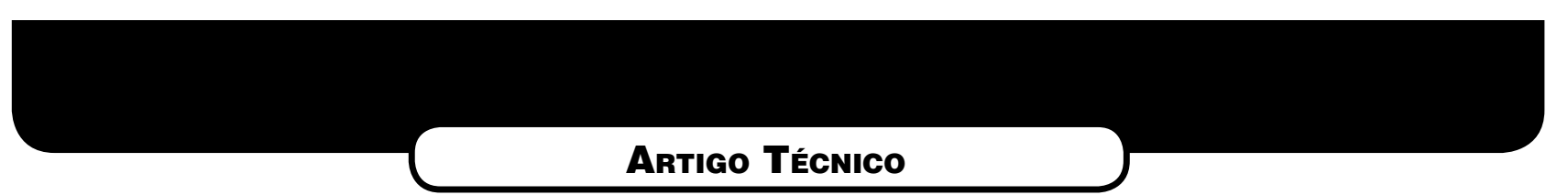

\title{
AVALIAÇÃo HIDRODINÂMICA DE REATOR UASB SUBMETIDO À VARIAÇÃO CÍCLICA DE VAZÃO
}

\section{HYDRODYNAMIC EVALUATION OF A UASB REACTOR SUBMITTED TO CYCLICAL FLOWRATE VARIATION}

\begin{abstract}
KARINA QUERNE DE CARVALHO
Engenheiro Civil pela Universidade Estadual de Maringá -UEM. Mestre em Hidráulica e Saneamento pela EESC-USP. Doutora em Hidráulica e Saneamento pela EESC-USP. Professora do Curso de Tecnologia em Gestão Ambiental e Engenharia Ambiental da UTFPR

\section{MoNique TOLEDO SALGADO}

Engenheira Civil pela Universidade Federal de Ouro Preto - UFOP. Mestre em Hidráulica e Saneamento pela EESC-USP. Doutoranda em Hidráulica e Saneamento pela EESC-USP

\section{FERnando Hermes Passig}

Engenheiro Sanitarista pela Universidade Federal de Santa Catarina - UFSC. Mestre em Hidráulica e Saneamento pela EESC-USP. Doutor em Hidráulica e Saneamento pela EESC-USP. Professor e Coordenador do Curso de Tecnologia em Gestão Ambiental e Engenharia Ambiental da UTFPR

\section{Eduardo Cleto Pires}

Engenheiro Mecânico pela Escola de Engenharia de São Carlos (EESC) - USP. Mestre em Engenharia Mecânica pela PUCRJ. Doutor e Livre-Docente em Hidráulica e Saneamento pela EESC-USP. Professor Titular do Departamento de Hidráulica e Saneamento da EESC-USP

Recebido: 10/04/07 Aceito: 06/05/08
\end{abstract}

\section{RESUMO}

Um reator UASB em escala piloto (160 l) foi usado com o objetivo de estudar seu comportamento hidrodinâmico quando submetido a variações cíclicas senoidais da vazão afluente. Os ensaios foram realizados com traçador eosina $Y$ para as condições operacionais: vazão média afluente constante e igual a $161 . \mathrm{h}^{-1}$ e tempo de detenção hidráulica de $10 \mathrm{~h}$ (ensaios $1 \mathrm{e}$ 2), e para vazão afluente submetida à variação senoidal de $40 \%$ (ensaios 3 e 4) e de 60\% (ensaio 5). A variação da concentração do traçador no efluente foi ajustada pelos modelos teóricos de dispersão de fluxo e de reatores em série. O reator UASB apresentou comportamento similar ao de reator de mistura completa para vazão média afluente constante e similar ao reator de fluxo pistonado com a aplicação das variaçôes senoidais cíclicas, sendo que o modelo de pequena dispersão apresentou melhor ajuste matemático.

PALAVRAS-CHAVE: Difusão, bio-reator, hidrodinâmica, traçador, fenômeno de cauda

\begin{abstract}
A bench scale UASB reactor (160l) was used in stimulus-response assays in order to evaluate its behaviour when submitted to cyclical sinusoidal variations of the influent flow rate. Assays were carried out with eosin $Y$ as the tracer in different operational conditions: constant mean influent flow rate of $16 l \cdot h^{-1}$ and hydraulic residence time of $10 \mathrm{~h}$ (assays 1 and 2), and influent flow rate submitted to sinusoidal variation of $40 \%$ (assays 3 and 4) and 60\% (assay 5). The variation of tracer concentration in the effluent was adjusted by the theoretical models of dispersion (low and high) and N-continuous stirred tank reactors in series. Complete mixture behaviour was noted to the application of the constant influent flow rate and a plug flow one to the application of the cyclical sinusoidal variations of the influent flow rate. The low dispersion model demonstrated the best mathematical adjustment in the RTD.
\end{abstract}

KEYWORDS: Diffusion, bioreactor, hydrodynamics, tracer, tailing phenomena

\section{INTRODUÇÃO}

A aplicação de modelos matemáticos para previsão do comportamento dinâmico de reatores UASB está recebendo atenção particular com a divulgação do modelo ADM 1 proposto pela IWA. Uma das etapas necessárias para uso desse modelo, ou de qualquer outro, é o conhecimento detalhado do comportamento hidrodinâmico.

A hidrodinâmica dos reatores anaeróbios tem papel importante porque pode influenciar a velocidade das reações biológicas, por meio de alterações na taxa de transferência de massa e a distribuição das reaçôes ao longo do reator. Como conseqüência da distribuição da biomassa e do encadeamento das reações bioquímicas, diferentes regiōes do reator apresentam composições diferentes, em função do tipo de escoamento imposto. 
Além disso, curtos-circuitos hidráulicos, caminhos preferenciais e zonas mortas (sem presença de substrato na alimentação) podem prejudicar a eficiência dos reatores no tratamento de águas residuárias devido à diminuição do volume útil e do tempo de detenção hidráulica dos reatores.

Brito e Melo (1997) avaliaram o comportamento hidrodinâmico de um reator UASB em escala de laboratório, com volume de aproximadamente $480 \mathrm{ml}$ e mantido à temperatura de $30^{\circ} \mathrm{C}$. O substrato era composto por mistura de ácidos acético e propiônico na proporção de 4,5:1,0. O reator foi operado com tempo de detenção hidráulica $(\mathrm{TDH})$ de $1,7 \mathrm{~h}$ e velocidade ascensional de $0,22 \mathrm{~m} \cdot \mathrm{h}^{-1}$. A imobilização do reator com $21 \mathrm{~kg} \cdot \mathrm{m}^{-3}$ de sólidos voláteis foi feita com biomassa anaeróbia granular proveniente de reator UASB em escala real tratando água residuária de indústria de farinha de trigo. Os ensaios de estímulo-resposta tipo pulso foram realizados com injeção de volume de $2 \mathrm{ml}$ de cloreto de lítio e concentração de $5 \mathrm{~g} \cdot \mathrm{l}^{-1}$ na linha de alimentação do reator UASB.

Os autores verificaram a presença de gradiente da concentração do substrato ao longo da altura do reator, o que pode indicar comportamento hidrodinâmico semelhante ao reator tipo tubular ideal. Isso ocorreu devido à baixa velocidade ascensional de operação aplicada ao reator e a insuficiente produção gasosa obtida para promover a turbulência necessária à mistura do fluido interno. O coeficiente de ajuste de 0,97 foi obtido para as curvas experimentais de distribuição do tempo de residência (DTR) quando foi aplicado o modelo de tanques em série (N-CSTR) com equivalência de 4 reatores de mistura completa. Os autores destacam o surgimento de cauda nas amostras do efluente do reator contendo cloreto de lítio, o que poderia indicar a presença de zonas estagnadas no reator.

Morgan-Sagastume et al (1997) estudaram a influência da posição do sistema de coleta de biogás no comportamento hidrodinâmico de um reator em escala piloto com volume de 840 l. O reator foi operado com TDH de 5,8 h e vazão média afluente de $3,45 \mathrm{~m}^{3} \cdot \mathrm{d}^{-1}$ e inoculado com 2641 de lodo anaeróbio granular. Os ensaios de estímulo-resposta tipo pulso foram realizados com injeção de volume de $10 \mathrm{ml} \mathrm{de}$ bromocresol verde e con- centração de $14,1 \mathrm{mg} \cdot \mathrm{l}^{-1}$ na linha de alimentação do reator. $\mathrm{O}$ bromocresol verde foi escolhido por não absorver ou adsorver na biomassa e por apresentar estabilidade nos parâmetros $\mathrm{pH}$ e potencial redox na operação do sistema com água de torneira.

Os autores verificaram que o posicionamento do coletor de biogás (como barreira física) mais próximo ao manto de lodo diminuiu a fração de volume morto no interior do reator ao introduzir uma zona de equalização de fluxo de vazão, ou seja, evitou o aparecimento de caminho preferencial no interior do reator e aumentou a eficiência do sedimentador. O comportamento hidrodinâmico do reator apresentou tendência a escoamento tubular com o posicionamento do coletor de biogás próximo ao manto de lodo.

Esse trabalho pretende avaliar o comportamento hidrodinâmico de um reator UASB em escala piloto (160 l) submetido a variaçóes cíclicas diárias de cargas orgânicas e hidráulicas de vazão com período de $24 \mathrm{~h}$. Com isso objetiva-se analisar a influência das variações cíclicas diárias de cargas orgânicas e hidráulicas em períodos curtos de duração iguais ou menores que $24 \mathrm{~h}$, comuns em esgoto de origem doméstica e freqüentemente encontradas em pequenas instalações de tratamento. Como primeira etapa do estudo, um levantamento da resposta hidrodinâmica do reator nessas condiçôes foi elaborado, variando-se senoidalmente a vazão média afluente em até $60 \%$, em valores inferiores e superiores. Posteriormente, os resultados experimentais obtidos foram comparados com modelos matemáticos de uso corrente na avaliação hidrodinâmica de reatores.

\section{METODOLOGIA}

\section{Reator}

Os ensaios de estímulo-resposta tipo pulso foram realizados em um reator anaeróbio de manta de lodo (UASB) em escala piloto confeccionado em PVC com 1,86 m de altura, $300 \mathrm{~mm}$ de diâmetro e volume total de 1601 (Figura 1). O reator UASB foi operado para estudar a influência das variaçôes cíclicas senoidais de cargas orgânicas e hidráulicas da vazão média afluente durante 370 dias.

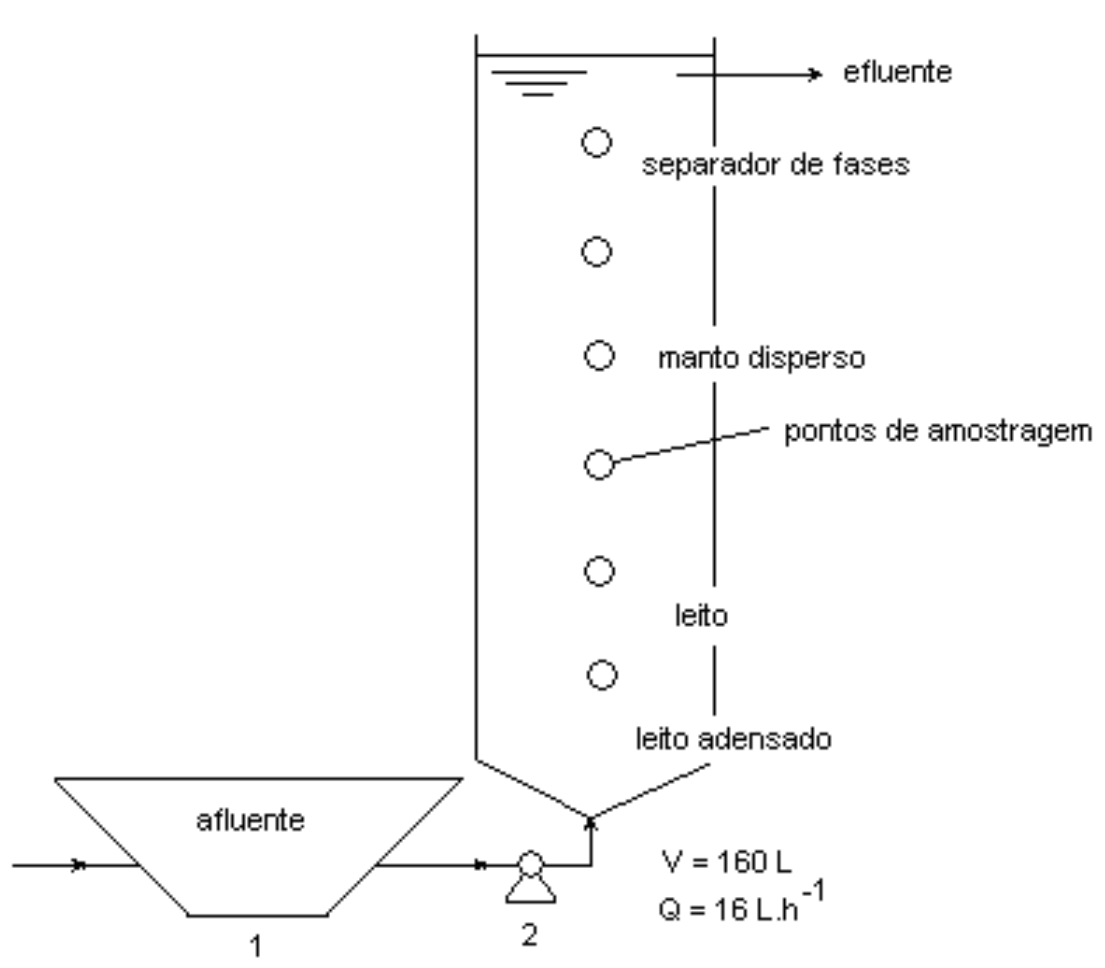

Figura I - Esquema do reator UASB em escala piloto. (I) Reservatório do afluente (590 L), (2) bomba dosadora 


\section{Inóculo}

O reator foi inoculado com aproximadamente $55 \mathrm{~L}$ de lodo anaeróbio granular proveniente de reator anaeróbio que trata água residuária de abatedouro de aves. Esse lodo foi escolhido por apresentar diversidade microbiana verificada por exames microbiológicos com microscopia ótica comum, de fluorescência e de contraste de fase com microscópio Leica DM LB (ob 100x), sistema de câmera digital Leica DC 200 e programa computacional Image Pro-Plus na versão 4.5.0. Os exames microbiológicos do inóculo identificaram predomínio de bacilos delgados e curvos; bacilos ovalados, bacilos com extremidades arredondadas, filamentos e cocos. Dentre as arquéias metanogênicas, predominaram bacilos fluorescentes e filamentos semelhantes a Metanosaeta sp., bacilos curvos fluorescentes e cistos de sarcinas e arquéias metanogênicas semelhantes a Metanosarcina sp.

Determinaçōes das concentrações de sólidos totais, sólidos totais voláteis e de sólidos totais fixos resultaram em aproximadamente 36 g.l $\mathrm{l}^{-1}, 30 \mathrm{~g} . \mathrm{l}^{-1} \mathrm{e}$ 6 g. $\mathrm{l}^{-1}$, respectivamente.

\section{Esgoto}

O reator foi alimentado continuamente com esgoto doméstico com concentração de matéria orgânica variando na faixa de $573 \mathrm{mg} \cdot \mathrm{l}^{-1}$ a 687 mg. $\mathrm{l}^{-1}$ em termos de DQO em todas as etapas dos ensaios de estímulo-resposta e mantido a temperatura ambiente. A caracterização do esgoto doméstico foi realizada por determinações das concentraçóes dos parâmetros de controle: DQO (bruta e filtrada), $\mathrm{pH}$, ácidos voláteis e alcalinidades total e a bicarbonato, sólidos totais e sólidos suspensos (Tabela 1).

\section{Operação do reator}

A Tabela 2 apresenta as três principais etapas de operação do reator UASB.

A etapa I teve início, após o período de partida em regime de batelada do reator por $24 \mathrm{~h}$. Nessa etapa o reator foi operado com vazão média afluente constante e igual a $16,01 . h^{-1}$ e tempo de detenção hidráulica de 10 h durante 309 dias. $\mathrm{O}$ estado de equilíbrio dinâmico aparente foi alcançado no $90^{\circ} \mathrm{dia}$ de operação do reator e verificado por

Tabela I - Caracterização do esgoto doméstico

\begin{tabular}{cccccc}
\hline Parâmetros & \multicolumn{5}{c}{ Substrato } \\
& $\mathrm{N}$ & $\bar{X}$ & DP & Min & Máx \\
\hline pH & 64 & 6,4 & 0,0 & 6,4 & 6,5 \\
Alcalinidade total $\left(\mathrm{mgCaCO}_{3} \cdot \mathrm{L}^{-1}\right)$ & 64 & 191 & 9 & 181 & 206 \\
DQO bruta $\left(\mathrm{mg} \cdot \mathrm{L}^{-1}\right)$ & 64 & 628 & 40 & 573 & 687 \\
DQO filtrada $\left(\mathrm{mg} \cdot \mathrm{L}^{-1}\right)$ & 64 & 419 & 19 & 394 & 447 \\
ST $\left(\mathrm{mg} \cdot \mathrm{L}^{-1}\right)$ & 64 & 627 & 62 & 442 & 747 \\
STV $\left(\mathrm{mg} \cdot \mathrm{L}^{-1}\right)$ & 64 & 453 & 76 & 307 & 578 \\
STF $\left(\mathrm{mg} \cdot \mathrm{L}^{-1}\right)$ & 64 & 174 & 34 & 135 & 205 \\
SST $\left(\mathrm{mg} \cdot \mathrm{L}^{-1}\right)$ & 64 & 97 & 9 & 85 & 107 \\
SSV $\left(\mathrm{mg} \cdot \mathrm{L}^{-1}\right)$ & 64 & 85 & 8 & 75 & 94 \\
SSF $\left(\mathrm{mg} \cdot \mathrm{L}^{-1}\right)$ & 64 & 12 & 6 & 8 & 19 \\
\hline
\end{tabular}

N: número de amostras; $\bar{X}$ : média aritmética; DP: desvio padrão; Min: valor mínimo; Máx: valor máximo

Tabela 2 - Condições operacionais do reator UASB

\begin{tabular}{ccccc}
\hline Etapa & $\begin{array}{c}\text { Período de operação } \\
(\text { dia })\end{array}$ & $\begin{array}{c}\text { Q } \\
\left(1 . h^{-1}\right)\end{array}$ & $\begin{array}{c}\text { TDH } \\
(\mathrm{h})\end{array}$ & $\begin{array}{c}\text { Velocidade ascensional } \\
\left(\mathrm{m}^{-1}\right)\end{array}$ \\
\hline I & 0 a 309 & 16,0 & 10 & 0,23 \\
II & 310 a 344 & mín $=14,5$ & 11 & 0,21 \\
& & máx $=17,5$ & 9 & 0,25 \\
III & \multirow{2}{*}{345 a 372 } & mín $=13,7$ & 12 & 0,20 \\
& & máx $=18,3$ & 8 & 0,26 \\
\hline
\end{tabular}

meio de determinação dos parâmetros de controle: DQO (bruta e filtrada), ácidos voláteis, $\mathrm{pH}$, alcalinidades total $\mathrm{e}$ a bicarbonato, sólidos suspensos fixos e voláteis e sólidos totais fixos e voláteis.

$\mathrm{Na}$ etapa II, o reator UASB foi submetido a variações senoidais cíclicas em valores inferiores e superiores a $40 \%$ da vazão média afluente, alcançando picos de mínimo e de máximo iguais a 9,6 $1 \cdot h^{-1}$ e $22,41 \cdot h^{-1}$, respectivamente, durante 34 dias.

A aplicação da variação senoidal, com período de $24 \mathrm{~h}$ e amplitudes de $40 \%$ e $60 \%$ do valor da vazão média, foi realizada por programa computacional que alterava percentualmente a vazão média afluente da bomba dosadora em intervalos de $15 \mathrm{~min}$. O comportamento do reator foi avaliado por determinação dos mesmos parâmetros de controle da etapa I, que indicou o alcance do estado de equilíbrio dinâmico aparente no $319^{\circ}$ dia de operação.

A etapa III teve início no $345^{\circ}$ dia de operação do reator com aplicação da variação senoidal cíclica em valores inferiores e superiores a $60 \%$ da vazão média afluente, alcançando picos de mínimo e de máximo iguais a $6,41 . \mathrm{h}^{-1}$ e $25,61 . \mathrm{h}^{-1}$, respectivamente, durante 27 dias. O comportamento do reator nessa etapa foi avaliado por meio da determinação dos mesmos parâmetros das etapas anteriores.

\section{Monitoramento}

Análises dos parâmetros DQO (bruta e filtrada), DBO, $\mathrm{pH}$, sólidos suspensos fixos e voláteis e sólidos totais fixos e voláteis foram realizadas em amostras do afluente (substrato) e do efluente para avaliar o comportamento do reator UASB durante todo o período de operação do reator (Tabela 3), de acordo com Standard Methods for the Examination of Water and Wastewater (1998). As análises de alcalinidade total e a bicarbonato foram realizadas em amostras do substrato e do efluente segundo metodologia descrita por Dillalo e Albertson (1961) e modificada por Ripley et al (1986). As concentrações de 
ácidos voláteis foram determinadas em amostras do substrato e do efluente de acordo com metodologia proposta por Dillalo e Albertson (1961 ) .

Os resultados experimentais obtidos nas três etapas de operação do reator UASB estão apresentados na Tabela 7.

\section{Procedimentos dos ensaios hidrodinâmicos}

Os procedimentos adotados para realização dos ensaios de estímuloresposta tipo pulso foram divididos em três etapas (Tabela 4). Na primeira etapa foram realizados dois ensaios de estímulo-resposta com o reator sendo operado com vazão média afluente constante igual a $161 . \mathrm{h}^{-1}$ e tempo de detenção hidráulica de $10 \mathrm{~h}$. Nas etapas II e III o reator foi submetido a variaçōes cíclicas senoidais da vazão afluente em valores inferiores e superiores a $40 \%$ e $60 \%$, respectivamente.

Todos os ensaios foram realizados com corante eosina Y como traçador após o reator UASB ter alcançado o estado de equilíbrio dinâmico aparente em cada etapa. Esse traçador foi escolhido em razão de suas características que permitem fácil detecção, elevada recuperação da massa injetada, estabilidade e segurança no manuseio. Outros autores também empregaram o traçador eosina Y em ensaios de estímulo resposta para determinação das curvas de distribuição do tempo de detenção hidráulica de reatores biológicos no tratamento de águas residuárias (Jiménez et al, 1988a; De Nardi et al, 1999).

O método colorimétrico de leitura de absorbância foi aplicado para determinação da concentração de eosina $\mathrm{Y}$ nas amostras do efluente do reator. As leituras dos comprimentos de ondas foram realizadas em espectrofotômetro Hach uv-vis, modelo DR/2000, com comprimento de onda de $516 \mathrm{~nm}$.

As condições operacionais do reator, a concentração e a massa molecular do traçador são apresentadas na Tabela 4. Medidas foram tomadas para garantir que a injeção do traçador fosse o mais similar possível de um pulso ideal. $\mathrm{O}$ volume de injeção do traçador foi de aproximadamente $20 \mathrm{ml}$ em cada ensaio e o tempo de injeção foi de aproximadamente $50 \mathrm{~s}$.

A concentração inicial do traçador usada no experimento foi baseada na solubilidade da eosina Y, observando sua faixa de detecção nas análi- ses colorimétricas. Com a realização do primeiro ensaio hidrodinâmico (800 mg de traçador), foi possível observar que a quantidade de massa de traçador injetada no reator poderia ser reduzida de $40 \%$ a $50 \%$ e as concentraçóes de eosina $\mathrm{Y}$ no efluente poderiam ser detectadas dentro da faixa de detecção adotada. Dessa maneira, optou-se por reduzir a quantidade de massa do traçador nos ensaios hidrodinâmicos subseqüentes.

O tempo total de duração dos ensaios foi determinado de tal forma que as amostras fossem coletadas pelo menos durante três vezes o tempo de detenção hidráulica teórico, com intervalos não superiores a uma hora. As amostras coletadas foram centrifugadas por cerca de 4 minutos para evitar a interferência da presença de sólidos na leitura das absorbâncias pelo método colorimétrico.

Os termos apresentados na Tabela 5 foram aplicados nas análises dos dados experimentais de acordo com Levens- piel (2000). As curvas experimentais da variação de concentração do traçador ao longo do tempo, $\mathrm{C}(\mathrm{t})$, foram normalizadas (área sobre a curva igual a 1) de acordo com Levenspiel (2000), resultando em curvas de distribuição do tempo de residência hidráulica $\left(\mathrm{E}_{\theta}\right)$ em função do tempo adimensional $(\theta)$. Após a normalização, foi possível calcular a variância para cada ensaio $\left(\sigma_{\theta}^{2}\right)$.

$\mathrm{O}$ ajuste das curvas experimentais de distribuição do tempo de detenção hidráulica em função do tempo adimensional foi realizado com base nos modelos teóricos uniparamétricos de dispersão - de pequena (PD) e de grande intensidade (GD) e de tanques em série (N-CSTR) (Tabela 6).

Os modelos de dispersão representam o reator avaliado por um reator de fluxo pistonado no qual ocorre dispersão axial do escoamento. Nesse modelo, o escoamento do fluido ocorre de forma ordenada através do reator, ou seja, não há mistura ou difusão ao longo do caminho de escoamento. $\mathrm{O}$

Tabela 3 - Parâmetros analisados, seus respectivos métodos e bibliografia utilizada

\begin{tabular}{|c|c|c|c|}
\hline Parâmetros & Método de análise & Método $\mathrm{n}^{\circ}$ & Referência \\
\hline Temperatura & - & - & - \\
\hline $\mathrm{pH}$ & Potenciométrico & 4500_H+ & APHA, 1998 \\
\hline Alcalinidade & Titulométrico & - & $\begin{array}{c}\text { Dillalo e Albertson (1961) } \\
\text { modificado por Ripley } \\
\text { et al (1986) }\end{array}$ \\
\hline DQO & Espectrofotométrico & 5220_D & APHA (1998) \\
\hline $\mathrm{DBO}$ & Titulométrico & 5210_D & APHA (1998) \\
\hline $\begin{array}{c}\text { Sólidos } \\
\text { suspensos }\end{array}$ & Gravimétrico & 2540_G & APHA (1998) \\
\hline Sólidos totais & Gravimétrico & 2540_E & APHA (1998) \\
\hline Ácidos voláteis & Titulométrico & - & Dillalo e Albertson (1961) \\
\hline
\end{tabular}

Tabela 4 - Características dos ensaios de estímulo-resposta realizados no reator $U A S B$

\begin{tabular}{cccccc}
\hline Etapas & Ensaios & $\begin{array}{c}\text { Tempo de } \\
\text { Detenção } \\
\text { Hidráulica } \\
(\mathrm{TDH})\end{array}$ & $\begin{array}{c}\text { Vazão } \\
\text { afluente }\end{array}$ & $\begin{array}{c}\text { Massa } \\
\text { aplicada } \\
\text { de traçador }\end{array}$ & $\begin{array}{c}\text { Concentraçáo } \\
\text { de traçador }\end{array}$ \\
\hline \multirow{2}{*}{1} & 1 & $(\mathrm{H})$ & $\left(1 . \mathrm{h}^{-1}\right)$ & $(\mathrm{mg})$ & $\left(\mathrm{mg} .20 \mathrm{ml}^{-1}\right)$ \\
& 2 & 10 & 16 & 800 & 40,0 \\
2 & 3 & 10 & 16 & 442 & 22,1 \\
& 4 & var.1 & $* 40 \% . \mathrm{Q}$ & 706 & 35,3 \\
3 & 5 & var. & $* 40 \% . \mathrm{Q}$ & 436 & 21,8 \\
\hline
\end{tabular}


modelo de tanques em série simula o comportamento do reator avaliado por $\mathrm{N}$ (número) reatores de mistura completa (ideais) em série. A mistura completa indica que o conteúdo está agitado e uniforme em todo o reator, ou seja, a corrente de saída (efluente) tem a mesma composição que o fluido no interior do reator. Essas características podem ser verificadas pelos parâmetros $\mathrm{D}$ (ou $\frac{\mathrm{D}}{\mathrm{uL}}$ ) para os modelos de pequena e grande dispersão ou pelo número (N) de reatores de mistura completa em série para o modelo N-CSTR. A estimativa desses parâmetros foi realizada pela variância dos dados de resposta apresentados na Tabela 6 .

A Tabela 5 apresenta um resumo das definições das variáveis empregadas nos modelos uniparamétricos para obtenção da curva de distribuição do tempo de residência hidráulica $\left(\mathrm{E}_{\theta}\right) \mathrm{em}$ função do tempo adimensional $(\theta)$.

Os modelos teóricos uniparamétricos de dispersão de pequena (PD) e de grande intensidade (GD) e de tanques em série (N-CSTR) são apresentados na Tabela 6 .
Para as etapas II e III, com aplicação das variações da vazão média afluente, foi necessário corrigir a vazão afluente para cada intervalo de tempo $(\mathrm{t})$. Como a vazão média afluente era controlada por programa computacional que simulava a variação senoidal, foi possível obter os valores das variações em cada intervalo de tempo de $15 \mathrm{~min}$.

\section{RESULTADOS E DISCUSSÃO}

A Tabela 7 apresenta um resumo dos resultados experimentais obtidos nas etapas I, II e III de operação do reator UASB, ou seja, submetido à vazão média afluente constante e a variaçôes senoidais cíclicas de $40 \%$ e de $60 \%$, respectivamente.

Pela Tabela 7 é possível observar que o reator apresentou comportamento estável quanto ao $\mathrm{pH}$ em todas as etapas, com valores variáveis de 6,2 a 6,6 no afluente e de 6,6 a 7,1 no efluente.

Os valores obtidos para as concentraçôes de alcalinidade total e a bi- carbonato no efluente foram superiores àqueles obtidos para o afluente em todas as etapas de operação do reator, o que indicou a capacidade de tamponamento do reator mesmo quando submetido a variações cíclicas da vazão afluente. As concentrações de ácidos voláteis no efluente resultaram em valores inferiores a $90 \mathrm{mgHAc}^{-1}$ nas três etapas de operação. Foi possível observar o acúmulo de ácidos no efluente com a aplicação das variaçôes senoidais cíclicas de vazão, principalmente nos períodos de aumento da vazão média para máxima. $\mathrm{O}$ aumento das concentrações de ácidos voláteis pode ter ocorrido devido à maior velocidade ascensional de fluxo, que acarretou em menor tempo de contato entre o substrato e a biomassa para a realização da metanogênese. Lew et al. (2004) e Leitão et al (2005) também observaram maiores concentraçôes de ácidos voláteis na operação de reatores UASB com tempos de detenção hidráulica reduzidos.

A eficiência do sistema na remoção de matéria orgânica diminuiu aproximadamente $13 \%$ e $21 \%$ com a

Tabela 5 - Definição das variáveis usadas para obtenção da curva de distribuição do tempo de residência hidráulica $\left(E_{\theta}\right)$ em função do tempo adimensional $(\theta)$

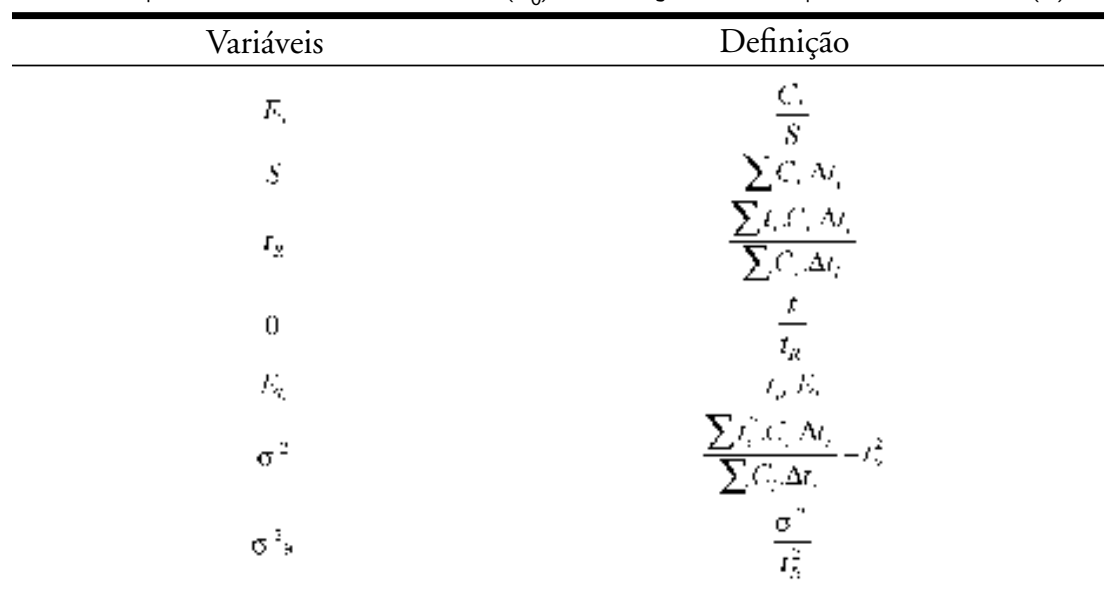

Tabela 6 - Definição das variáveis usadas para obtenção da curva de distribuição do tempo de residência hidráulica $\left(\mathrm{E}_{\theta}\right)$ em função do tempo adimensional $(\theta)$

\begin{tabular}{ccc}
\hline Modelo & Parâmetro & Equação \\
\hline $\begin{array}{c}\text { Dispersão de pequena } \\
\text { intensidadade } \\
\text { Dispersão de grande } \\
\text { intensidadade } \\
\text { (tanque aberto) } \\
\text { Tanques de mistura completa } \\
\text { em série }\end{array}$ & $\sigma^{2}{ }_{\theta}=2\left(\frac{D}{u \cdot L}\right)$ & $E_{\theta}=\frac{1}{2 \sqrt{\pi(D / u \cdot L)}} \exp \left[-\frac{(1-\theta)^{2}}{4(D / u \cdot L)}\right]$ \\
\hline
\end{tabular}




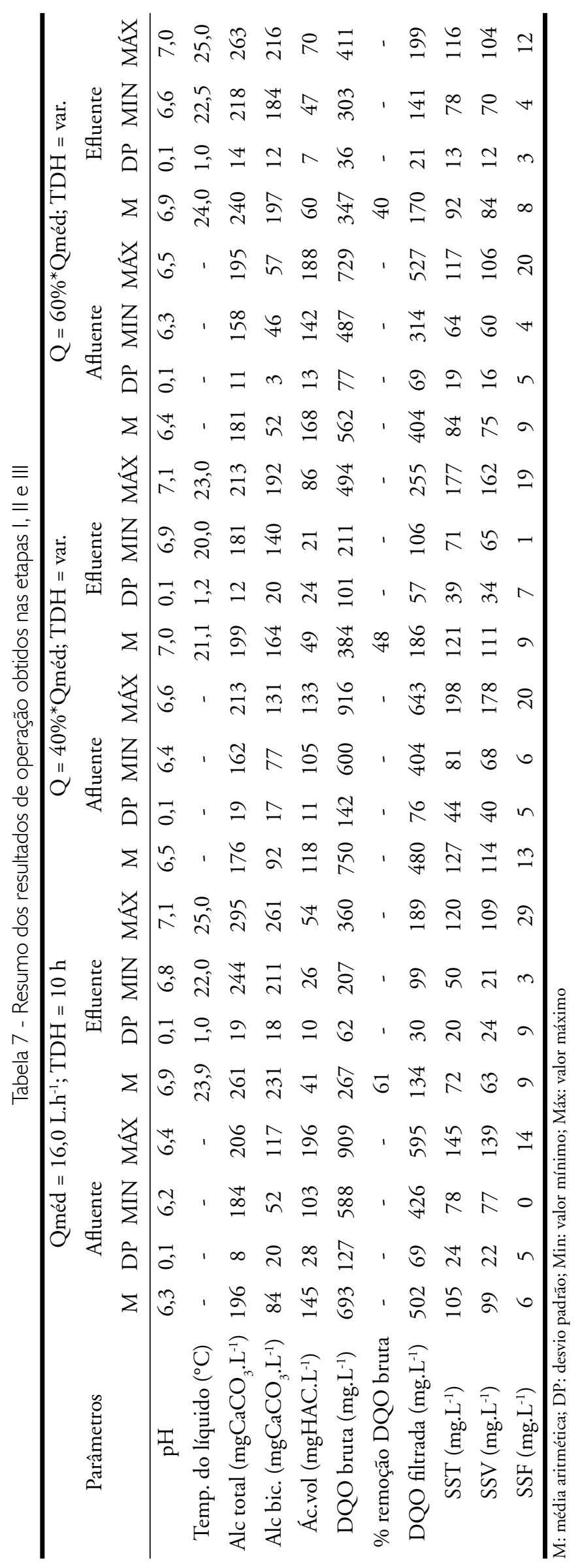


aplicação das variaçōes senoidais cíclicas da vazão média afluente de $40 \%$ e de $60 \%$, respectivamente. A eficiência do sistema foi prejudicada pelo arraste de sólidos no efluente, provavelmente pela formação dos bolsões devido ao acúmulo de biogás no manto de lodo. Com a aplicação das variações senoidais cíclicas da vazão afluente de $40 \%$ e de $60 \%$, foi possível observar maior arraste de sólidos nos períodos de aumento da velocidade ascensional de fluxo. Esse fenômeno também foi verificado por Mahmoud et al (2003). Aiyuk et al (2003) ressaltam que o aumento do arraste de sólidos no efluente pode ocorrer devido à ruptura (quebra) do grânulo do lodo anaeróbio usado no tratamento de esgoto doméstico de baixa concentração.

\section{Resultados dos ensaios hidrodinâmicos}

As curvas de variação das concentraçōes de eosina $\mathrm{Y}$ ao longo do tempo nas amostras do efluente do reator são apresentadas na Figura 2.

O lento decaimento observado nas concentrações de eosina $\mathrm{Y}$ ao longo do tempo pode indicar o fenômeno de "cauda", tanto para os ensaios realizados com vazão média afluente constante de $161 . h^{-1}$ e tempo de detenção hidráulica de aproximadamente $10 \mathrm{~h}$ (Figura 2, a e b), quanto para os experimentos realizados com variação senoidal cíclica da vazão média afluente de $40 \%$ e de $60 \%$ (Figura 2, c, d, e). O efeito da cauda provavelmente ocorreu devido aos fenômenos de difusão em zonas mortas do reator, adsorção do traçador na biomassa do reator ou curto circuito hidráulico (Levenspiel, 2000). Outros estudos também observaram o efeito de cauda longa (Stevens et al, 1986; Jiménez et al, 1988a; Jiménez et al, 1988b; de Nardi et al, 1999; Lima, 2001).

Jiménez et al (1988a) observaram o fenômeno de cauda devido à difusão da eosina $\mathrm{Y}$ e de outros traçadores que distorcem o formato das curvas de resposta e levam ao erro do ajuste dos modelos matemáticos e da interpretação do comportamento hidrodinâmico de reatores.

De Nardi et al (1999) observaram o efeito da cauda na determinação do comportamento hidrodinâmico do reator anaeróbio horizontal com leito fixo (RAHLF ) com lodo imobilizado em meio suporte de cerâmica. Os ensaios de estímulo-resposta tipo pulso foram realizados com os traçadores dextrano azul, bromocresol verde e eosina $\mathrm{Y}$ em meio abiótico e o efeito cauda observado pode ter ocorrido devido ao fenômeno de difusão do traçador no meio suporte utilizado.

Lima (2001) avaliou a hidrodinâmica de reator anaeróbio horizontal com leito fixo (RAHLF) sendo operado com água e esgoto em diversos estágios de operação e vazão volumétrica e com diferentes traçadores, entre eles a eosina Y. O autor constatou visualmente a adsorção desse traçador na espuma com a abertura do reator após os ensaios. $\mathrm{O}$ traçador permaneceu retido na espuma após uma série de lavagens e expulsão do volume estagnado em uma matriz. Apesar do fenômeno observado, o autor constatou que o traçador foi adequado para o monitoramento dos desvios do escoamento e do comprometimento do volume útil ao longo dos estágios de operação. Observe-se que no reator estudado no presente trabalho não foi utilizado meio suporte.

Mesmo após a centrifugação das amostras do efluente para os ensaios de estímulo-resposta 3, 4 e 5, foi possível verificar algumas variaçôes nas leituras de absorbância devido à presença de sólidos nessas amostras (Figura 2, c, d e e). Os pontos isolados das curvas de variação da concentração de eosina $\mathrm{Y}$ ao longo do tempo foram desconsiderados na análise matemática por apresentarem concentração anormal de traçador.

Os valores obtidos para recuperação da massa do traçador injetada no reator resultaram em: $85 \%$ e $86 \%$ para os ensaios 1 e 2 , respectivamente; $88 \%$ e $90 \%$ para os ensaios 3 e 4 , respectivamente e $90 \%$ para o ensaio 5 .

Brown et al (1984) verificaram $85 \%$ de recuperação do traçador bromofenol azul nas amostras do efluente de reatores de lodo ativado em escala real nos ensaios hidrodinâmicos. Jiménez et al (1988a) obtiveram recuperação de traçador nas amostras do efluente variando de 41 a 51\% em ensaios com eosina $\mathrm{Y}$ na presença de biomassa; Brito e Melo (1997) alcançaram recuperação de $95 \%$ do cloreto de lítio usado em estudo hidrodinâmico de reator UASB com biomassa anaeróbia granular; Lima (2001) obteve porcentagem de recuperação de $90 \%$ da massa injetada ao avaliar a hidrodinâmica do reator RAHLF tratando esgoto sanitário; Passig (2005) obteve recuperação de traçador variando de $42 \%$ a $89 \%$ na operação de reator UASB em escala real $\left(18,8 \mathrm{~m}^{3}\right)$ tratando esgoto sanitário à temperatura média de $24^{\circ} \mathrm{C}$.

A Tabela 8 apresenta os resultados obtidos com o ajuste das curvas de distribuição do tempo de residência pelos modelos matemáticos teóricos, de acordo com Levenspiel (2000).

Observa-se em todos os ensaios que o tempo de detenção hidráulica real obtido por meio da curva DTR variou entre 14 e 16 horas. Os valores experimentais obtidos foram superiores ao TDH teórico por apresentarem diferenças significativas de $40 \%$ e de $60 \%$ nos ensaios 1 e 2 , respectivamente e de $50 \%$ nos ensaios 3, 4 e 5 em relação ao tempo de detenção hidráulica teórico de aproximadamente $10 \mathrm{~h}$. Esses resultados demonstraram atraso na resposta do traçador, o que pode indicar existência de zonas mortas no interior do reator ou adsorção do traçador na biomassa. $\mathrm{O}$ traçador teria se difundido nestas zonas mortas, sendo liberado aos poucos, o que provoca atraso em sua resposta na saída do reator e gera o fenômeno de cauda longa, como foi observado nas curvas experimentais.

Stevens et al (1986) notaram que os tempos de detenção hidráulica médios estimados a partir das curvas DTR foram aproximadamente 100\% superiores do que os tempos teóricos em um reator anaeróbio de leito fluidizado devido à difusão do traçador Rodamina WT no biofilme.

Observando os dados da Tabela 8 , nota-se que na etapa 1 (sem variação de vazão), o modelo teórico de N-CSTR em série fornece resultados iguais a 5 e 4 reatores e o modelo de pequena dispersão valores iguais a $0,112 \mathrm{e}$ 0,121 . Passig (2005) constatou que o reator UASB equivale a 5 reatores de mistura perfeita em série e obteve valor de 0,11 para o modelo de pequena dispersão. Portanto, pode-se concluir que esses valores encontrados estão muito próximos aos relatados na literatura técnico-científica.

Ainda na Tabela 8, nas etapas 2 e 3 observa-se aumento do número de N-CSTR em série e diminuição do valor referente ao modelo de pequena dispersão, provavelmente devido ao aumento da amplitude da variação da vazão afluente. O aumento da amplitude de variação de vazão média afluente ocasionou aumento do N-CSTR para 11 reatores de mistura perfeita em 

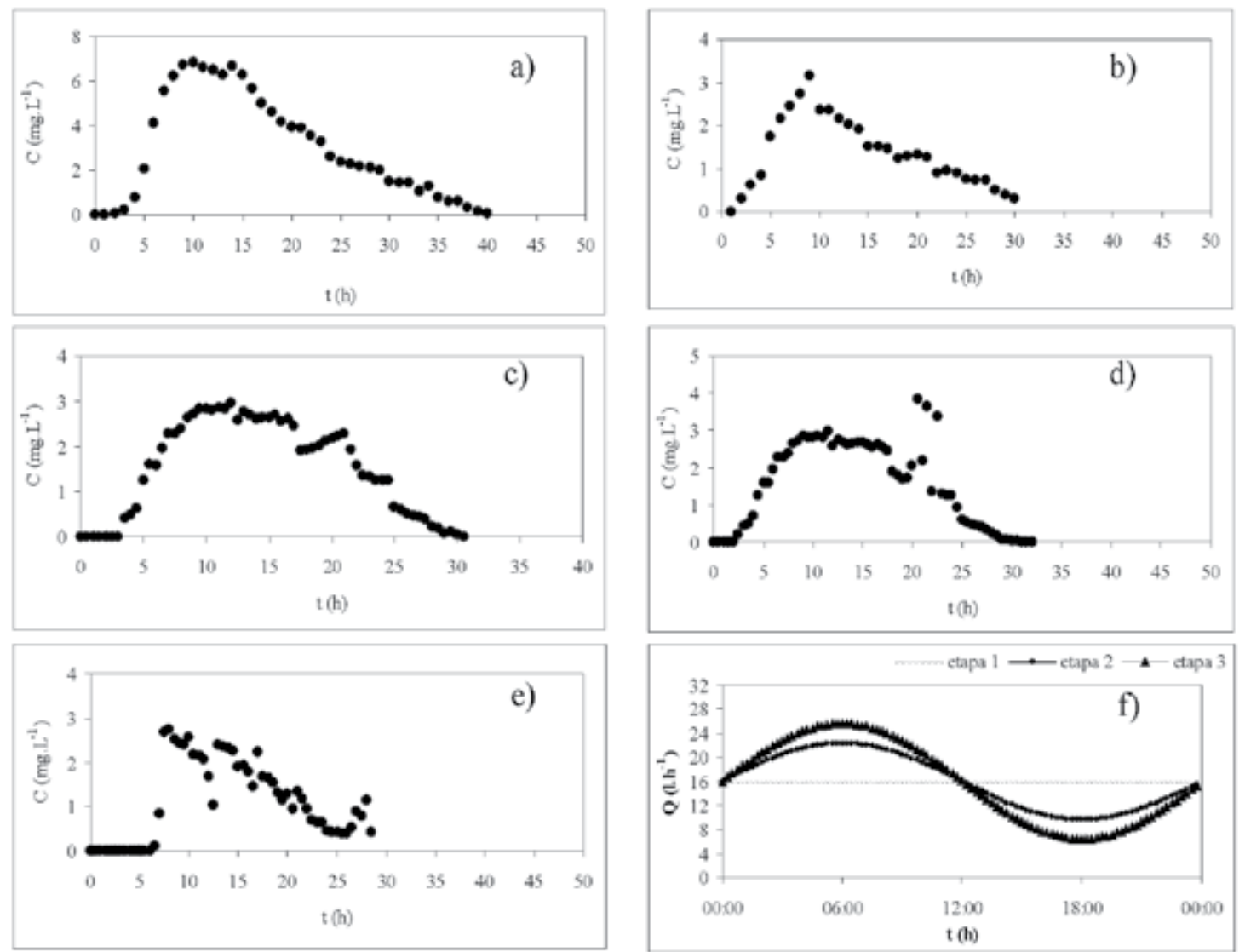

Figura 2 - Curvas de variação da concentração de eosina $Y$ ao longo do tempo nas amostras de efluente do reator para os ensaios de estímulo-resposta: $Q=161 . h^{-1}$ e TDH=I0h: $a$ - ensaio $I$, b - ensaio 2; $Q=40 \% .0$ e TDH= var.: c - ensaio 3, d - ensaio 4; $Q=60 \% .0$ e TDH = var.: e - ensaio 5; f - variação da vazão afluente

série e diminuição do valor de pequena dispersão para valor igual a 0,045 . Com isso o comportamento hidrodinâmico do reator se aproxima do reator de fluxo pistonado. Cabe salientar que os valores do modelo de grande dispersão não sofreram alteração em função do aumento da amplitude de variação da vazão afluente ao reator.

A Tabela 9 apresenta os resultados de coeficientes de correlação obtidos para os modelos matemáticos teóricos.

Na Tabela 9, pode-se observar que o modelo matemático de pequena dispersão apresentou os melhores ajustes dos dados experimentais para os ensaios com vazão média afluente constante e com variação senoidal cíclica da vazão média afluente.

Os valores de tempo de detenção hidráulica (TDH) e do parâmetro $\mathrm{N}$ não apresentaram diferenças significativas, o que indicou grau de mistura semelhante para os ensaios realizados. Os resultados experimentais obtidos para TDH apresentaram diferenças significativas de $40 \%$ e de $60 \%$ nos ensaios 1 e 2 , respectivamente e de $50 \%$ nos ensaios 3, 4 e 5 em relação ao tempo de detenção hidráulica teórico de $10 \mathrm{~h}$.

As curvas experimentais de distribuição do tempo de residência (DTR) obtidas com o ajuste de modelos matemáticos são apresentadas na Figura 3.

Observa-se que os modelos de pequena dispersão (PD) e de grande dispersão (GD) apresentaram melhor ajuste aos dados experimentais, apesar de inicialmente os ensaios não respeitarem suas premissas $(\mathrm{D} / \mathrm{uL}<0,01$ e dispersão idêntica dentro e fora do volume de controle). Entretanto, isto não significa que o ajuste tenha sido satisfatório, porque, mesmo neste modelo, foi grande a dispersão em relação aos valores experimentais. Como o modelo N-CSTR previu a ocorrência de uma concentração máxima de traçador, a qual não ocorreu, seu ajuste tornou-se comprometido (Figura 3 a, b, c, d e e).

Nos perfis experimentais, foi detectada atenuação do pico devido ao retardo da passagem do traçador da porção posterior ao pico (efeito de cauda).

\section{CONCLUSÕES}

$\mathrm{Na}$ avaliação hidrodinâmica constatou-se que o reator UASB apresentou comportamento próximo ao de reator de mistura completa com aproximadamente 4 ou 5 reatores de mistura completa (N-CSTR) em série, para o ensaio sem variação de vazão afluente. Com o aumento da amplitude da variação da vazão afluente do reator constatou-se que o comportamento do reator se aproxima de um reator de fluxo pistonado. 
Tabela 8 - Parâmetros obtidos com o ajuste dos dados experimentais para reator UASB

\begin{tabular}{cccccc}
\hline Etapas & Ensaios & TDH & N-CSTR & $\begin{array}{c}\text { Pequena } \\
\text { dispersão } \\
(\mathrm{PD})\end{array}$ & $\begin{array}{c}\text { Grande } \\
\text { dispersão } \\
(\mathrm{GD})\end{array}$ \\
\hline 1 & 1 & 16 & 5 & 0,112 & 0,075 \\
& 2 & 14 & 4 & 0,121 & 0,079 \\
2 & 3 & 15 & 8 & 0,064 & 0,075 \\
& 4 & 15 & 7 & 0,072 & 0,075 \\
& 5 & 15 & 11 & 0,045 & 0,075 \\
\hline
\end{tabular}

Tabela 9 - Coeficientes de correlação obtidos com o ajuste dos resultados experimentais pelos modelos teóricos

\begin{tabular}{ccccc}
\hline Etapas & Ensaios & $\begin{array}{c}\text { Coeficiente de correlação }(\mathrm{r}) \\
\text { Pequena } \\
\text { dispersão }\end{array}$ & $\begin{array}{c}\text { Grande } \\
\text { dispersão }\end{array}$ & $\begin{array}{c}\text { N-CSTR } \\
\text { em série }\end{array}$ \\
\hline 1 & 1 & 0,809 & 0,809 & 0,663 \\
& 2 & 0,890 & 0,867 & 0,720 \\
& 3 & 0,890 & 0,772 & 0,742 \\
& 4 & 0,795 & 0,779 & 0,714 \\
& 5 & 0,771 & 0,704 & 0,705 \\
\hline
\end{tabular}
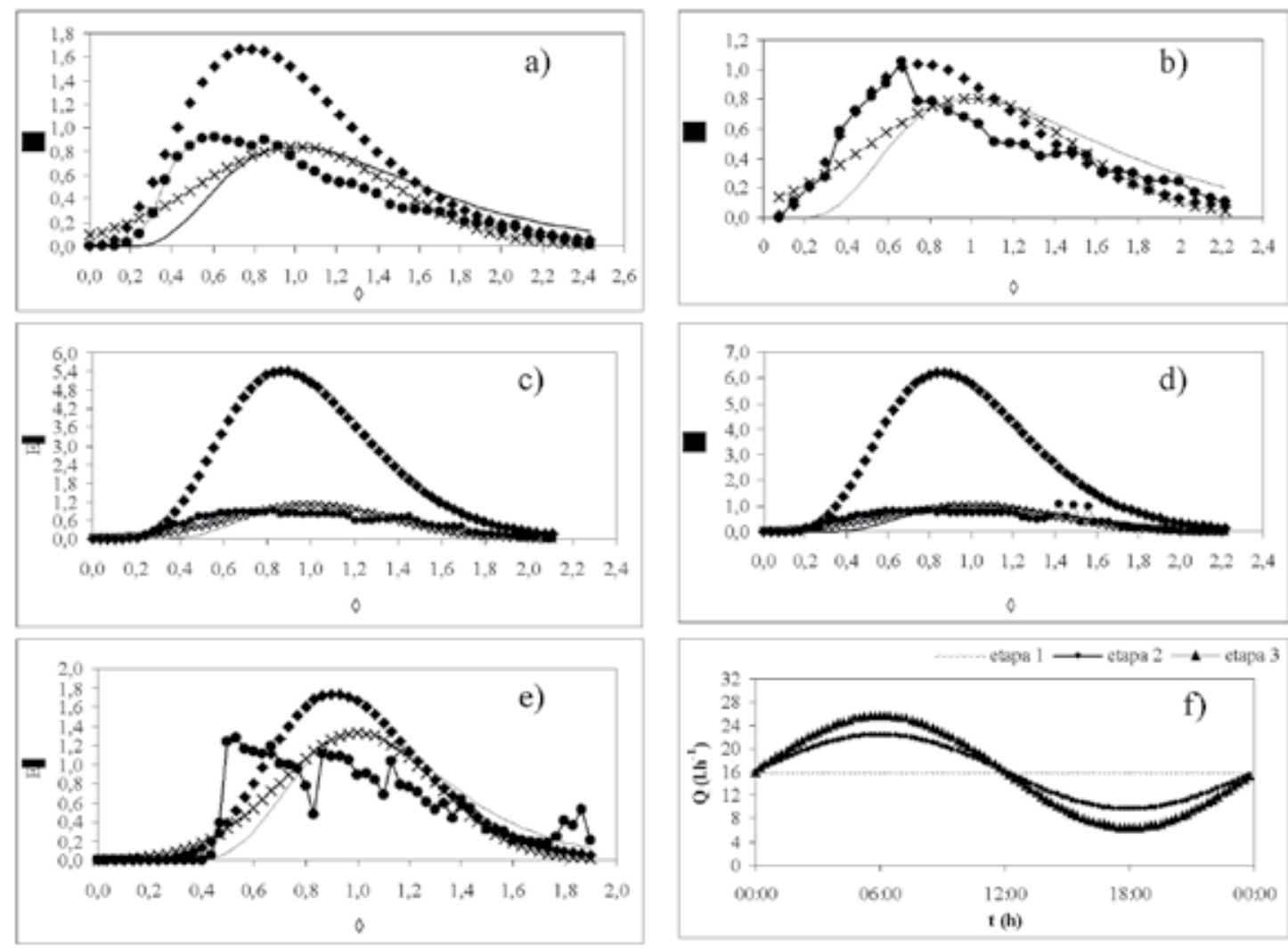

Figura 3 - Curvas de DTR obtidas experimentalmente com uso de eosina $Y$ em diferentes condições operacionais do reator UASB: $Q=161 . h^{-1}$ e $T D H=10 h: a-$ ensaio $I, b-$ ensaio $2 ; Q=40 \% . Q$ e TDH = var.: c - ensaio 3, d - ensaio 4; $Q=60 \%$.Q e TDH = var.: e - ensaio 5 ; f - variação da vazão afluente. --- Dados experimentais; -x- pequena dispersão; $\nabla N$-CSTR em série; - grande dispersão 
Apesar da aplicação das variaçōes senoidais cíclicas de $40 \%$ e $60 \%$, os parâmetros tempo de detenção hidráulica e grau de mistura do reator não apresentaram diferenças significativas quando comparados àqueles parâmetros obtidos para vazão média afluente constante.

Ao comparar o tempo de detenção hidráulica teórico com o determinado pelas curvas de DTR obtidas experimentalmente, verificou-se atraso de aproximadamente $50 \%$ da resposta do traçador que poderia indicar existência de zonas mortas hidrodinâmicas no interior do reator. O fenômeno de cauda observado nas curvas obtidas é resultante da difusão do traçador nessas zonas mortas e de sua lenta liberação.

\section{AGRADECIMENTOS}

Pelo apoio recebido, os autores agradecem à Fundação de Amparo à Pesquisa do Estado de São Paulo FAPESP (Projeto temático $\mathrm{n}^{\circ}$. 01/05489-0, Bolsa de doutorado da Eng. Karina Querne de Carvalho - no. 02/00683-6), e ao Departamento de Hidráulica e Saneamento da Universidade de São Paulo em São Carlos - Escola de Engenharia de São Carlos.

\section{REFERÊNCIAS}

AIYUK, S. et al. Anaerobic and complementary treatment of domestic sewage in regions with hot climates - a review. Bioresource Technology, v.97, n. 17, p. 2225-241, Nov. 2006.

BRITO, A.G.; MELO, L.F. A simplified analysis of reaction and mass transfer in UASB and EGSB reactors. Environmental Technology, v. 18, p. 35-43, Sept. 1997.

BROWN, L; RHEAD, M.M.; HILL, D. The use of bromophenol blue as a tracer in sewage works. Water Research, v. 18, n. 9, p. 1083-087, Jan. 1984.

DE NARDI, I.R.; ZAIAT, M; FORESTI, E. Influence of the tracer characteristics on hydrodynamic models of packed-bed bioreactors. Bioprocess Engineering, v. 21, p. 469-76, Nov. 1999.

JIMÉNEZ, B; NOYOLA, A; CAPDEVILLE, B. Selected dyes for residence time distribution in bioreactors. Biotechnology Techniques, v. 2, p. 77-82. 1988a.

JIMÉNEZ, B. et al. Dextran blue colorant as a reliable tracer in submerged filters. Water Research, v. 22, p. 1253-257, Oct. 1988b.

LEITÃO, R.C. et al. The effect of operational conditions on the performance of UASB reactors for domestic wastewater treatment. Water Science and Technology, v. 52, n. 1-2, p. 299-305. 2005.

LEVENSPIEL, O. Engenharia das Reações Quimicas. 3 ed. São Paulo. Ed. Edgard Blücher Ltda, 563 p, 2000.
LEW, B. et al. UASB reactor for domestic wastewater treatment at low temperatures: a comparison between a classical UASB and Hybrid UASB-filter reactor. Water Science and Technology, v. 49, n. 11-12, p. 295-301. 2004.

LIMA, C.A.A. Tratamento de esgoto sanitário em reator horizontal de leito fixo (RAHLF) - Escala Piloto. São Carlos, Tese (doutorado) - Escola de Engenharia de São Carlos, Universidade de São Paulo. 165p, 2001.

MAHMOUD, N. et al. Solids removal in upflow anaerobic reactors, a review. Bioresource Technology, v. 90, n. 1, p. 1-9, Oct. 2003.

MORGAN-SAGASTUME, J.M.; JIMÉNEZ, B.; NOYOLA, A. Tracer studies in a laboratory and pilot scale UASB reactor. Environmental Technology, v. 18, p. 817-25. 1997.

PASSIG, F.H. Reator anaeróbio híbrido para o tratamento de esgoto sanitário. São Carlos, 148p. Tese (doutorado) - Escola de Engenharia de São Carlos, Universidade de São Paulo. 2005.

STEVENS, D.K.; BERTHOUEX, P.M.; CHAPMAN, T.W. The effect of tracer diffusion in biofilm on residence time distributions. Water Research, v. 20, n. 3, p. 369-75, Mar. 1986.

\section{Endereço para correspondência:}

Karina Querne de Carvalho

Rua Mamborê, 987 - Centro

87302-I40 Campo Mourão - PR

- Brasil

Telefax: (44) 3523-4I56

E-mail: kaquerne@gmail.com

\section{LISTA DE SÍMBOLOS}

$\mathrm{C}_{\mathrm{i}}=$ concentração de traçador, $[\mathrm{M}][\mathrm{L}]^{-3}$

$\mathrm{D}=$ coeficiente de dispersão, $\left.[\mathrm{L}]^{2} \cdot[\mathrm{T}]^{-1}\right]$

$\frac{\mathrm{D}}{\mathrm{uL}}=$ número de dispersão do reator

$E_{\mathrm{i}}=$ curva de distribuição de idade de saída do traçador, $[\mathrm{T}]^{-1}$;

$E_{i}=$ Função de distribuição do tempo de residência hidráulica

$\mathrm{N}$ = número de reatores em série

$\mathrm{S}$ = área sob a curva concentração

- tempo; $[\mathrm{M}] .[\mathrm{T}] .[\mathrm{L}]^{-3}$

$\mathrm{t}_{\mathrm{R}}=$ tempo de médio de residência obtido da curva DTR, [T]

$\mathrm{i}=$ tempo de residência médio adimensional

$v^{2}=$ variância, $[T]^{2}$

$v_{i}{ }^{2}=$ variância adimensional

$\mathrm{ta}=$ tanque aberto 